\title{
Comparative evaluation of a new lactation curve model for pasture-based Holstein-Friesian dairy cows
}

\author{
S. A. Adediran, ${ }^{\star 1}$ D. A. Ratkowsky, ${ }^{*}$ D. J. Donaghy, $\dagger^{2}$ and A. E. O. Malau-Aduli*3 \\ ${ }^{*}$ Animal Science and Genetics, School of Agricultural Science/Tasmanian Institute of Agriculture, University of Tasmania, \\ Private Bag 54 Hobart, TAS 7001, Australia \\ †Dairy Research Centre, Tasmanian Institute of Agriculture, PO Box 3532 Burnie, TAS 7320, Australia
}

\section{ABSTRACT}

Fourteen lactation models were fitted to average and individual cow lactation data from pasture-based dairy systems in the Australian states of Victoria and Tasmania. The models included a new "log-quadratic" model, and a major objective was to evaluate and compare the performance of this model with the other models. Nine empirical and 5 mechanistic models were first fitted to average test-day milk yield of Holstein-Friesian dairy cows using the nonlinear procedure in SAS. Two additional semiparametric models were fitted using a linear model in ASReml. To investigate the influence of days to first test-day and the number of test-days, 5 of the best-fitting models were then fitted to individual cow lactation data. Model goodness of fit was evaluated using criteria such as the residual mean square, the distribution of residuals, the correlation between actual and predicted values, and the Wald-Wolfowitz runs test. Goodness of fit was similar in all but one of the models in terms of fitting average lactation but they differed in their ability to predict individual lactations. In particular, the widely used incomplete gamma model most displayed this failing. The new log-quadratic model was robust in fitting average and individual lactations, and was less affected by sampled data and more parsimonious in having only 3 parameters, each of which lends itself to biological interpretation.

Key words: lactation model, pasture-based, dairy cow, test-day milk yield

Received June 29, 2011.

Accepted April 2, 2012

${ }^{1}$ Current address: Genetic Epidemiology, Dalla Lana School of Public Health, University of Toronto, 155 College Street, Toronto, ON M5T 3M7, Canada.

${ }^{2}$ Current address: Institute of Veterinary, Animal and Biomedical Sciences, Massey University, Private Bag 11-222, Palmerston North 4442, New Zealand.

${ }^{3}$ Corresponding author: Aduli.MalauAduli@utas.edu.au or aduli40@ yahoo.co.uk

\section{INTRODUCTION}

In Australia, dairy cows rely on fodder from pasture for about $70 \%$ of feed energy (Dairy Australia, 2008). Compared with those in stall-fed cows, milk yield patterns in pasture-based dairy cows are more prone to fluctuations due to seasonality of pasture production, pasture management practices, undetected subclinical diseases, nutritional interventions, and other management practices used to mitigate feed shortfalls (Kolver and Muller, 1998; Olori et al., 1999; Collard et al., 2000; Tekerli et al., 2000). Short lactations arising from synchronized calving patterns to match pasture availability, occasional occurrence of double peaks, and irregular milk recording logistics are also some peculiar features of pasture-based dairy systems. Under such varying environmental conditions, high-genetic-merit cows are more likely to exhibit depressed milk yields (Kolver and Muller, 1998; Olori et al., 1999).

The lactation curve, which can be modeled using mathematical functions (Beever et al., 1991; Schaeffer, 2004), generally takes the shape of an increase to a peak 4 to 8 wk into lactation, followed by a gradual decline until dry-off. These functions have the advantage of minimizing random variation while simultaneously summarizing the lactation profile into biologically interpretable parameters. The resulting curve parameter estimates can be further analyzed to predict future yields from incomplete lactation records, detect deviation of an individual cow or a herd of cows from the expected performance, provide early estimates of 305-d milk yields for breeding decisions (Jensen, 2001; Schaeffer, 2004), and to monitor responses to changes in management factors (Morant and Gnanasakthy, 1989; Pollott, 2000). However, variation among individual cows (Olori et al., 1999), data properties (Macciotta et al., 2005), and the aforementioned peculiarities accentuate differences in curve patterns, hitherto referred to as irregular lactations (Macciotta et al., 2005). It is desirable to have a model that is easy to apply, biologically meaningful, less constrained by atypical lactations, and suitable for describing short lactations 
(Pollott and Gootwine, 2000) to reduce milk-recording costs. For the first time, the new log quadratic (LQ) model is being proposed because of its peculiar ability to fit both inclining and declining lactation rates from initial milk yield, thus being less constrained by the a priori assumption of an incline to peak yield that all other models make.

The mathematical functions available to model lactation profiles are many, and include empirical (linear or nonlinear), mechanistic, and semiparametric types (Sherchand et al., 1995; Schaeffer, 2004). The incomplete gamma (IG) function (Wood, 1967) is the most widely used to model the entire lactation in dairy cows. Empirical models, often criticized for overestimation of milk yield in early lactation, for having a predetermined curve shape, and failure to relate curve parameters to mammary gland physiology (Pollott, 2000; Macciotta et al., 2005), are still the models of choice by dairy researchers and economists (Tozer and Huffaker, 1999) for their relative ease of application and good fitness to diverse lactations.

Although mechanistic models (Neal and Thornley, 1983; Pollott, 2000; Grossman and Koops, 2003) offer insight into the mammary gland physiological processes such as parenchyma cell proliferation, differentiation, and apoptosis (Knight and Wilde, 1993; Knight et al., 1998), they are often over-parameterized and fit the data poorly based on current monthly milk recording systems (Pollott, 2000). For their flexibility in fitting time-series for events with various curves, semiparametric functions such as Legendre polynomials (Kirkpatrick et al., 1994) and cubic splines (White et al., 1999) are also suitable for lactation modeling.

Variation in the goodness of fit of lactation models in diverse production systems has been reported (Tozer and Huffaker, 1999; Macciotta et al., 2005). Olori et al. (1999) observed that the polynomial function (Ali and Schaeffer, 1987) was the best of 5 models compared in a farm-based study, whereas Garcia and Holmes (2001) found no difference in the fit of diphasic and linearbased split-plot models for pasture-based Holstein-Friesian cows. Papajcsik and Bodero (1988) evaluated 20 lactation models and concluded that the IG model ( $Y t$ $\left.=a t^{b} e^{-c t}\right)$ and its derivative $\left[Y t=a t^{b} / \cosh (c t)\right]$ best fitted the data from cows in a subtropical environment. In comparison, Val-Arreola et al. (2004) fitted 5 lactation models to data from small-scale and intensive dairy systems in Mexico and reported that the mechanistic model proposed by Dijkstra et al. (1997) gave statistically significant parameter estimates and the lowest residual mean squares. Silvestre et al. (2006) evaluated 7 functions, including 3 Legendre polynomial and cubic splines, in stall-feeding systems and concluded that the spline model best fitted the lactation data. In addition to variation in individual animal production patterns (Olori et al., 1999) and differences in production systems (Tozer and Huffaker, 1999; Val-Arreola et al., 2004), the mathematical property (Macciotta et al., 2005) and lactation data properties such as day at first test-day, number of available records, and the interval between test-days (Berry et al., 2005; Silvestre et al., 2006) have been shown to affect the goodness of fit of a model

The objectives of this paper were to evaluate the goodness of fit of a new LQ model for fitting average and individual cow lactations and compare it with the state-of-the-art lactation models. Further, we evaluated the effect of days to first test-day and number of testday records on the goodness of fit of the 5 best-fitting models.

\section{MATERIALS AND METHODS}

\section{Sites, Climatic Conditions, and Production Systems}

The 2 data sets used in the study were from the Australian states of Tasmania and Victoria, which have similar climatic conditions. In addition, the production system in southeast Gippsland, Victoria, is similar to that used in dairying in Tasmania. Average maximum temperatures are $30^{\circ} \mathrm{C}\left(86^{\circ} \mathrm{F}\right)$ and $21^{\circ} \mathrm{C}\left(70^{\circ} \mathrm{F}\right)$ in Victoria and Tasmania, respectively, in summer (December to February) and $15^{\circ} \mathrm{C}\left(59^{\circ} \mathrm{F}\right)$ and $12^{\circ} \mathrm{C}\left(54^{\circ} \mathrm{F}\right)$, respectively, in winter (June to August). The annual rainfall varies from 626 to $2,400 \mathrm{~mm}$. Most dairy herds in Tasmania are located in the northwest, whereas the research farm supplying DATA2 is located in the southeast of Victoria. The relatively mild winter in both sites offers unique opportunities for year-round grazing where precipitation is not limiting. Dairying in both states is characterized by seasonal, low-input, pasture-based milk production. Productivity increases are achieved through an increasing use of hay and grain supplements. The Holstein-Friesian breed constitutes about $70 \%$ of the dairy cows milked in both states.

Daily milk yields are automatically recorded into a database through on-line milking machines for each individually tagged cow. Test-day milk yield records are morning milk yields collected once a month on average for each registered herd. Evening milk yields are estimated based on standards determined by the Australian Dairy Herd Improvement Scheme (ADHIS, 2008). Milk yields from sick or mastitic cows are not collected and are treated as missing for the month. 


\section{Data Management}

Two data sets of Holstein-Friesian cows from the Australian states of Tasmania and Victoria (DATA1 and DATA2, respectively) were used in the study; DATA1 comprised 76,760 records $(9,505$ lactations) from 154 dairy herds collected from 2005 to 2007 , and DATA2 comprised 19,987 records (2,138 lactations) from a single dairy research farm collected from 1998 to 2005. The data were edited to exclude cows with incorrect or missing birth or calving dates, lactation length $<100$ or $>305 \mathrm{~d}$, and fewer than 5 test-day records for a particular lactation. Records of cows with first postpartum recorded DIM $<4 \mathrm{~d}$ or $>120 \mathrm{~d}$ and greater than parity 5 were also excluded from the analysis. Parities $>2$ were pooled and referred to as parity 3 . Lactation stage in months (test-day) was obtained as the number of days from calving following the first $15 \mathrm{~d}$ postpartum, which was taken as the first test-day postpartum. Seven age groups were defined in DATA1: $18 \leq$ age $<24,25 \leq$ age $<30,31 \leq$ age $<36,37 \leq$ age $<42,43 \leq$ age $<54$, $55 \leq$ age $<67,68 \leq$ age $<75$ in age classes 1 to 7 , with number of records 11,947, 6,890, 8,426, 7,540, 14,890, 12,867 , and 10,241 respectively. Summary statistics for herd characteristics are presented in Table 1.

\section{Lactation Models}

The various lactation models used to evaluate testday milk yield (L/d) of the Holstein-Friesian cow are shown in Table 2. We propose a new second-degree polynomial model, the LQ model, for modeling lactation in dairy cows. Expressed in its general form, the second-degree polynomial is a parabola with the equation $\log Y_{t}=a_{1} x^{2}+a_{2} x+a_{3}$, where $x$ is log-transformed time such as DIM, but it can be written in a standard or vertex form as

$$
\log Y_{t}=a(b-\log t)^{2}+c
$$

where $\log Y_{t}$ is the $\log _{\mathrm{e}}$-transformed test-day milk yield, logt is the $\log _{\mathrm{e}}$-transformed time $t$ in days, weeks, or months in milk, $a \neq 0$, and $b$ and $c$ are parameters of the model. Parameter $a$ controls the rate of incline to the peak and the rate of postpeak decline, $b$ is the logtransformed day at peak milk yield, and $c$ is the logtransformed peak milk yield. Parameter $b$ is not only the value of logt at which maximum milk production occurs but is also the axis of symmetry of the parabola.

To facilitate equivalent comparison of the LQ with the IG and modified gamma (MG; Morant and Gnanasakthy 1989) models, the LQ was also fitted to test-day milk yield directly (i.e., in an untransformed form):

$$
Y_{t}=\exp ^{\left[a(b-\log t)^{2}+c\right]} .
$$

\section{Statistical Analysis}

Average Lactation. To determine the average lactation curve of pasture-based Holstein-Friesian cows, the test-day milk yield of DATA1 was adjusted using PROC MIXED (SAS Institute, 2002), according to the model

$$
\begin{aligned}
Y_{i j k l m n o}= & \mathrm{L}_{\mathrm{i}}+H_{j}+T D_{k}+C Y_{l}+P_{m} \\
& +\mathrm{AGE}_{\mathrm{n}}+e_{i j k l m n o},
\end{aligned}
$$

where $Y_{i j k l m n o}$ is the ijklmnoth observation on test-day milk yield of lactation $i$ with fixed effects; $H_{j}$ of $j$ th herd $(j=1,2 \ldots 154), T D_{k}$ of $k$ th test-day $(k=1,2 \ldots 10)$ being $15,45 \ldots 285 \mathrm{~d}$ in milk, $C Y_{l}$ of $l$ th calving year $(l$ $=1,2,3), P_{m}$ of $m$ th parity $(m=1,2,3)$ and $\mathrm{AGE}_{\mathrm{n}}(\mathrm{n}$ $=1 \ldots 7)$. The lactation effect $(\mathrm{L})$ was treated as a random effect nested within herd, and $e_{i j k l m n o}$ is a random sampling effect of the lactation with mean zero and variance $\sigma_{e}^{2}$. Multiple lactations on the same cow were assumed uncorrelated. Interaction terms were initially included in the model but proved to be not significant and were subsequently dropped.

Least squares means of test-day milk yield were obtained from this model and used in fitting the average lactation (AL) curve of the Holstein-Friesian cow. Test-day milk yield and test-days (lactation stage)

\begin{tabular}{|c|c|c|c|c|c|c|c|c|c|}
\hline Data set & Year & \multicolumn{3}{|c|}{ Number } & & Parity $^{1}$ & & \multicolumn{2}{|c|}{ Milk yield/d } \\
\hline DATA1 & 2005-2007 & 154 & 9,505 & 76,760 & 18,098 & 21,578 & 37,084 & 12.7 & 5.34 \\
\hline
\end{tabular}
were fitted to each of the lactation models in turn using the Marquardt's iterative method of the nonlinear

Table 1. Summary of the data sets used in the study

${ }^{1}$ Number of herds, cows, and lactations in parities 1,2 , and $\geq 3$. 
Table 2. The mathematical representation, source, and number of parameters of the lactation models used in the study

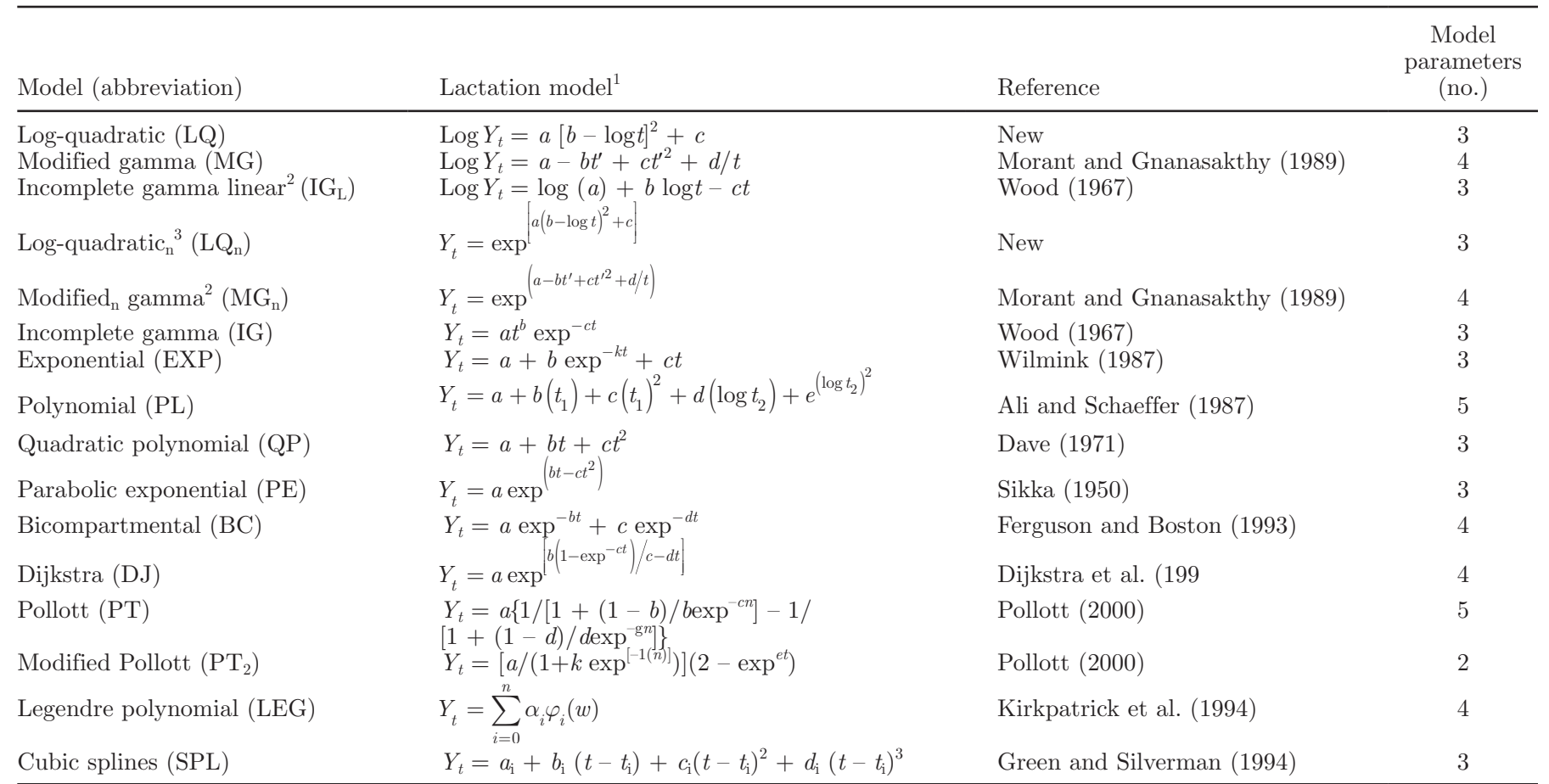

${ }^{1} \mathrm{Y}_{\mathrm{t}}=$ test-day milk yield $(\mathrm{L} / \mathrm{d}) ; \mathrm{t}=\mathrm{DIM} ; a, b, c, d, g, \varphi$ and $w$ are parameters that define the scale and shape of the curve; $\mathrm{t}^{\prime}\left(\mathrm{MG}_{\mathrm{f}}\right.$ and $\left.\mathrm{MG}_{\mathrm{n}}\right)$ $=(\mathrm{DIM}-150) / 100 ; \mathrm{t}_{1}$ and $\mathrm{t}_{2}(\mathrm{PL})$ are $\mathrm{t} / 305$ and $305 / \mathrm{t}$, respectively; $\mathrm{n}(\mathrm{PT}$, and PT2) $=\mathrm{t}-150 ;$ and $\mathrm{k}$ is a constant.

${ }^{2}$ Log-transformed IG.

${ }^{3}$ Untransformed model.

(NLIN) procedure of SAS (SAS Institute, 2002). The cubic spline (SPL) and Legendre polynomial (LEG) models were fitted as linear models in ASREML (Gilmour et al., 2002). To facilitate comparison with LQ, the IG (Wood, 1967) was also fitted in log-linear form, whereas the LQ and MG were fitted to test-day milk yield. The fitted empirical models were IG, MG, exponential (EXP; Wilmink, 1987), polynomial (PL; Ali and Schaeffer, 1987), quadratic polynomial (QP; Dave, 1971), parabolic exponential (PE; Sikka, 1950), and LQ. The fitted modified empirical functions were the incomplete gamma $\left(\mathbf{I G}_{\mathbf{L}}\right)$, modified gamma $\left(\mathbf{M G}_{\mathbf{n}}\right)$, and the log-quadratic modified $\mathbf{L Q}\left(\mathbf{L Q}_{\mathbf{n}}\right)$. The fitted mechanistic models were the bicompartmental (BC; Ferguson and Boston, 1993), Dijkstra (DJ; Dijkstra et al., 1997), Pollott (PT; Pollott, 2000), and the modified Pollott $\left(\mathbf{P T}_{2}\right)$, and the semiparametric models included the LEG (Kirkpatrick et al., 1994) and the SPL (Green and Silverman, 1994). The mathematical functions, source, and number of parameters of the models are shown in Table 2. The EXP model was fitted as a 3-parameter model with the constant parameter $(k)$ set at 0.46 , this being the best fitting value for average mean yield in a preliminary analysis of the data sets, during which the starting values of the NLIN procedures were also determined. The parameters of the PT and DJ models were constrained using the bound statement in SAS (bound $>0$ ), otherwise the models failed to converge.

In all models, $Y t$ is test-day milk yield $(\mathrm{L} / \mathrm{d})$, at time $t$ (DIM); $a, b, c, d, e, \alpha_{i}$, and $\varphi$ are parameters that define the scale and shape of the curve; $t^{\prime}$ (MG and $\left.\mathrm{MG}_{\mathrm{n}}\right)=(\mathrm{DIM}-150) / 100 ; t_{1}$ and $t_{2}(\mathrm{PL})$ are $t / 305$ and $305 / t$, respectively; $n\left(\mathrm{PT}\right.$, and $\left.\mathrm{PT}_{2}\right)=t-150$; and $k$ is a constant. In all PT models, parameter $a$ is the maximum milk secretion potential, $b$ and $d$ are proportions of milk yield potential and milk yield loss at parturition, respectively, and $c$ and $\mathbf{e}$ are the growth and death rate parameters of the 2 logistic curves, respectively. On the other hand, parameters $b$ and $d(\mathrm{BC})$ and $b$ and $c$ (DJ) represent the rate of cell proliferation and death, respectively. In the LEG model,

$$
w=2\left(\frac{t-t_{\min }}{t_{\max }-t_{\min }}\right)-1,
$$

where $w$ is lactation time unit ranging from -1 to +1 , $t=$ test day, $t_{\min }=15$, and $t_{\max }=285$.

Other lactation parameters of the $\mathrm{AL}$, such as the peak milk yield (PY), day at peak yield, total milk yield to $305 \mathrm{~d}$ (TMY), and lactation persistency, were 
I - Empirical models vs. LQ

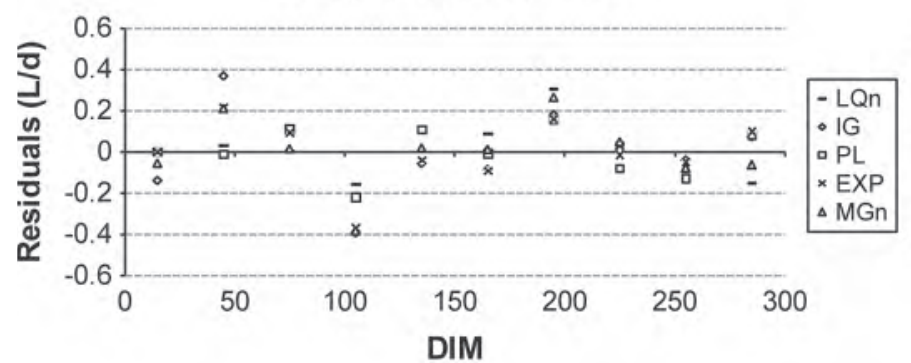

III - Semi-parametric models vs. LQ

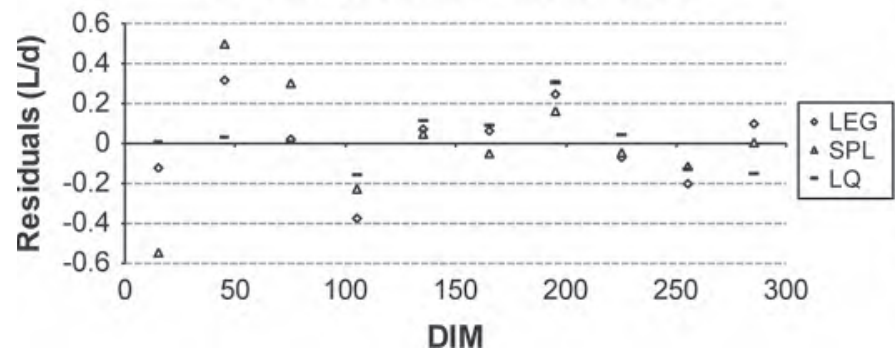

II - Mechanistic models vs. LQ

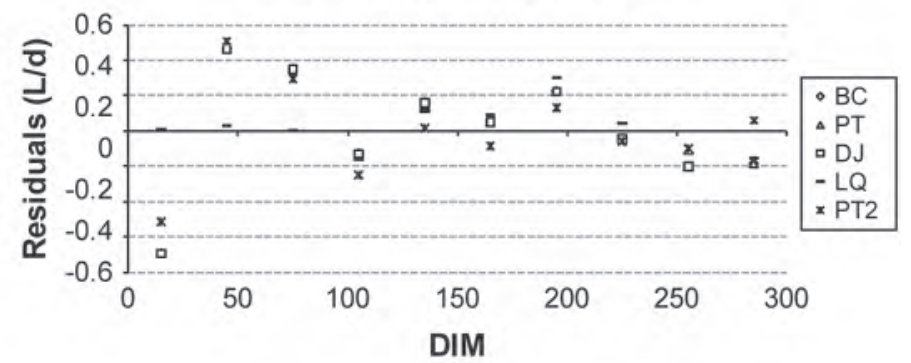

IV - Log-transformed empirical models vs. LQn

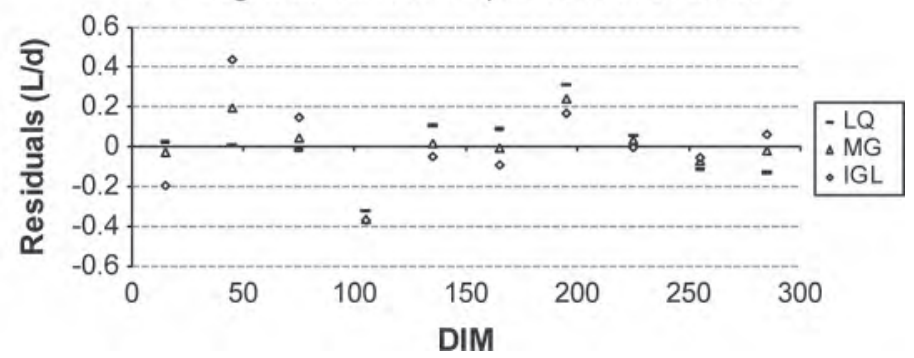

Figure 1. Comparison of plots of residuals against DIM from fitting average lactation (DATA1) to the log-quadratic and other lactation models. Panel I: - LQn = modified log-quadratic; $\diamond \mathrm{IG}=$ incomplete gamma; (Wood, 1967); $\square \mathrm{PL}=$ polynomial (Ali and Schaeffer, 1987); $\times$ $\mathrm{EXP}=$ exponential (Wilmink, 1987); $\Delta$ MGn = modified MG (Morant and Gnanasakthy, 1989). Panel II: $\diamond$ BC $=$ bicompartmental (Ferguson and Boston, 1993); $\Delta$ PT = Pollott (2000); $\square$ DJ = (Dijkstra et al., 1997); - LQ = log-quadratic; $\times$ PT2 = modified Pollott. Panel III: $\diamond$ LEG $=$ Legendre polynomial (Kirkpatrick et al., 1994); $\Delta \mathrm{SPL}=$ cubic splines (Green and Silverman, 1994); - LQ = log-quadratic (untransformed). Panel IV: - LQ = log-quadratic; $\Delta \mathrm{MG}=$ modified gamma (Morant and Gnanasakthy, 1989); $\diamond \mathrm{IG}_{\mathrm{L}}=$ log-transformed incomplete gamma (Wood, 1967).

estimated from the curve parameters for each model (Table 3). To obtain a uniform and comparable value of persistency across models, persistency was defined here as the ratio of the difference in daily milk yield $(\mathrm{mL} / \mathrm{d})$ at DIM 60 and 270 to the number of days during that same period using the formula

$$
\mathrm{P}_{\text {lact }}=\left(\mathrm{MY}_{60}-\mathrm{MY}_{270}\right) / 210
$$

where $\mathrm{P}_{\text {lact }}$ is the persistency of lactation, and $\mathrm{MY}_{270}$ and $\mathrm{MY}_{60}$ are test-day milk yield on 270 and 60 DIM, respectively. Cows with lower $\mathrm{P}_{\text {lact }}$ values are more persistent than those with higher values. These days were chosen because, for most pasture-based dairy cows, peak milk yield occurs before or at d 60 postpartum, whereas lactations would last $270 \mathrm{~d}$ or more in typical annual-calving systems.

Model Evaluation for Average Lactation. The goodness of fit of each model fitted to the AL was evaluated based on the analysis of residuals. Measures of prediction error used included the residual mean square (RMS), the magnitude and distribution of residuals represented as the plot of residuals against lactation stage (Figure 1), and the correlation between observed and predicted test-day milk yield. The Bayesian infor- mation criterion (BIC; Leonard and Hsu, 2001) was used to compare models. Further, the AL parameter estimates of each model (Table 4) were used to predict test-day daily milk yield on every 10th day in lactation; that is, DIM $=10,20,30$, and so on. Thus, 30 predicted values were obtained for each model. These were used to compute a new residual mean square $\left(\mathbf{R M S} \mathbf{S}_{\mathbf{W}}\right)$ as a measure of goodness of fit for each model using the formula according to Pollott and Gootwine (2000):

$$
R M S_{W}=\frac{\sum_{t=1}^{N}\left(M_{r P D}-M_{r H C}\right)^{2}}{(n-N)},
$$

where $M_{r P D}$ and $M_{r H C}$ were the predicted and $\mathrm{AL}$ lactation yields on each DIM, respectively; $n$ was the number of test-day milk records (30) in the lactation; and $N$ was the number of parameters in the model (see Table 4). The resulting $R M S_{W}$ was used to rank the models in order of best to worst goodness of fit. The log-transformed models (LQ, MG, and $\mathrm{IG}_{\mathrm{L}}$ ) were compared separately from the other models. This ranking and the number of parameters in the models were used in selecting 5 models that were used in the further analysis of individual cows' lactations. 
Table 3. Data groups showing number of cows, mean (standard deviation) of milk yield used for testing the effect of days to first test-day, and number of observations (in parentheses following data group name) on the goodness of fit of 5 of the best fitting lactation models

\begin{tabular}{lccc}
\hline & \multicolumn{3}{c}{ Number of test-days } \\
\cline { 2 - 4 } $\begin{array}{l}\text { Days to first } \\
\text { test-day }\end{array}$ & 5 & $6-7$ & $>7$ \\
\hline $\begin{array}{l}\text { DATA1 } \\
<60\end{array}$ & L60A & L60B & L60C \\
& $407,12.9(3.6)$ & $500,12.8(4.0)$ & $500,12.6(3.7)$ \\
$>60$ & G60A (127) & G60B $(299)$ & G60C (291) \\
& $127,11.6(3.7)$ & $300,10.6(3.3)$ & $292,12.0(3.2)$ \\
$\begin{array}{l}\text { DATA2 } \\
<60\end{array}$ & - & L60B & L $60 \mathrm{C}$ \\
$>60$ & - & $188,18.2(5.9)$ & $1350,19.2(6.3)$ \\
& & - & G60C $(291)$ \\
& & & $588,18.9(6.2)$ \\
\hline
\end{tabular}

Individual Cow Lactations. The entire test-day milk yields of individual cows from DATA1 and DATA2 were fitted to the 5 best-fitting models using the NLIN procedures in SAS as described in the previous section. The objective was to determine how each model performed with diverse lactation data. To determine the effect of data availability on the goodness of fit of the 5 models, both data sets were partitioned according to the number of postpartum days before the first test-day and the number of test-days.

Two groups were determined by whether the first test day was less than $(\mathbf{L})$ or greater than $(\mathbf{G}) 60 \mathrm{~d}$, respectively. Within each of these groups, the data were further subdivided into 3 classes (A, B, and C), based upon whether $5,6-7$ or $>7$ lactation records were available, respectively. Peak milk yield in our data occurred on or before d 60 postpartum. Thus, DATA1 had 6 partitions; namely, L60A (first test day $<60$, number of records $=5$ ), G60A (first test day $>60$, number of records $=5$ ), L60B (first test-day $<60$ and number of records $=6$ or 7 ), and so on to the sixth partition, G60C (first test-day $>60$ and number of records $>7$ ). All available data were used in all but the L60B and L60C groups (DATA1), in which a random sample of 500 lactations was taken from 1,957 and 6,390 lactations, respectively. Due to limitations in data size, DATA2 was partitioned into 3 groups: L60C, G60B, and $\mathrm{G} 60 \mathrm{C}$, as defined above. The interval between recorded test-days was not considered, as neither of the data sets had records for all test-days (1 to 305) or had uniform test-day intervals. The number of lactations per group and the mean and standard deviation of milk yield are shown in Table 3.

Model Evaluation for Individual Cow Lactations. The following criteria were used to compare the goodness of fit of the models fitted to individual lactations and the partitioned data.
(1) Average and standard deviation of error (residuals), which measures the error in absolute terms (Congleton and Everett, 1980) without recognizing its variation through the lactation.

(2) Association between actual and predicted milk yield, measured as the proportion of explained variation in the response variables, was calculated as

$$
\mathrm{R}^{2}=1-\mathrm{SSE} / \mathrm{CSS}
$$

where SSE is the error sum of squares and CSS is the corrected sum of squares of milk yield.

(3) The randomness of the distribution of the errors in serially correlated data can be quantified, measured and tested by the Wald-Wolfowitz (W, nonrandom distribution for $P<0.05$ ) runs tests (Constantinides, 1988). The Wald-Wolfowitz runs test is a nonparametric test applied to the errors of each lactation. A significant test $(P<$ 0.05 ) indicates the presence of longer than expected sequences of positive or negative residuals.

(4) Differences between extremes of observed and predicted milk yield represented by the percentage of estimated milk yields $\leq 0$ (EXLO) or greater than the highest observed yield (EXHI; Silvestre et al., 2006) were also used as a measure of goodness of fit. Mean test-day milk yields were 12.7 and $18.9 \mathrm{~L} / \mathrm{d}$, with only 25 and 32 records having milk yield $>40 \mathrm{~L} / \mathrm{d}$ in DATA1 and DATA2, respectively. This corresponds to an expectation of $0.03 \%$ (DATA1) and $0.16 \%$ (DATA2). Predicted milk yield values were examined for yield $\leq 0$, which is not expected biologically, or $>40$, an expectation higher than observed. In either case, the model was consid- 
Table 4. Predicted parameter estimates, residual means squares (RMS), and Bayesian information criteria (BIC) of lactation models fitted to average lactation data of Holstein-Friesian dairy cows

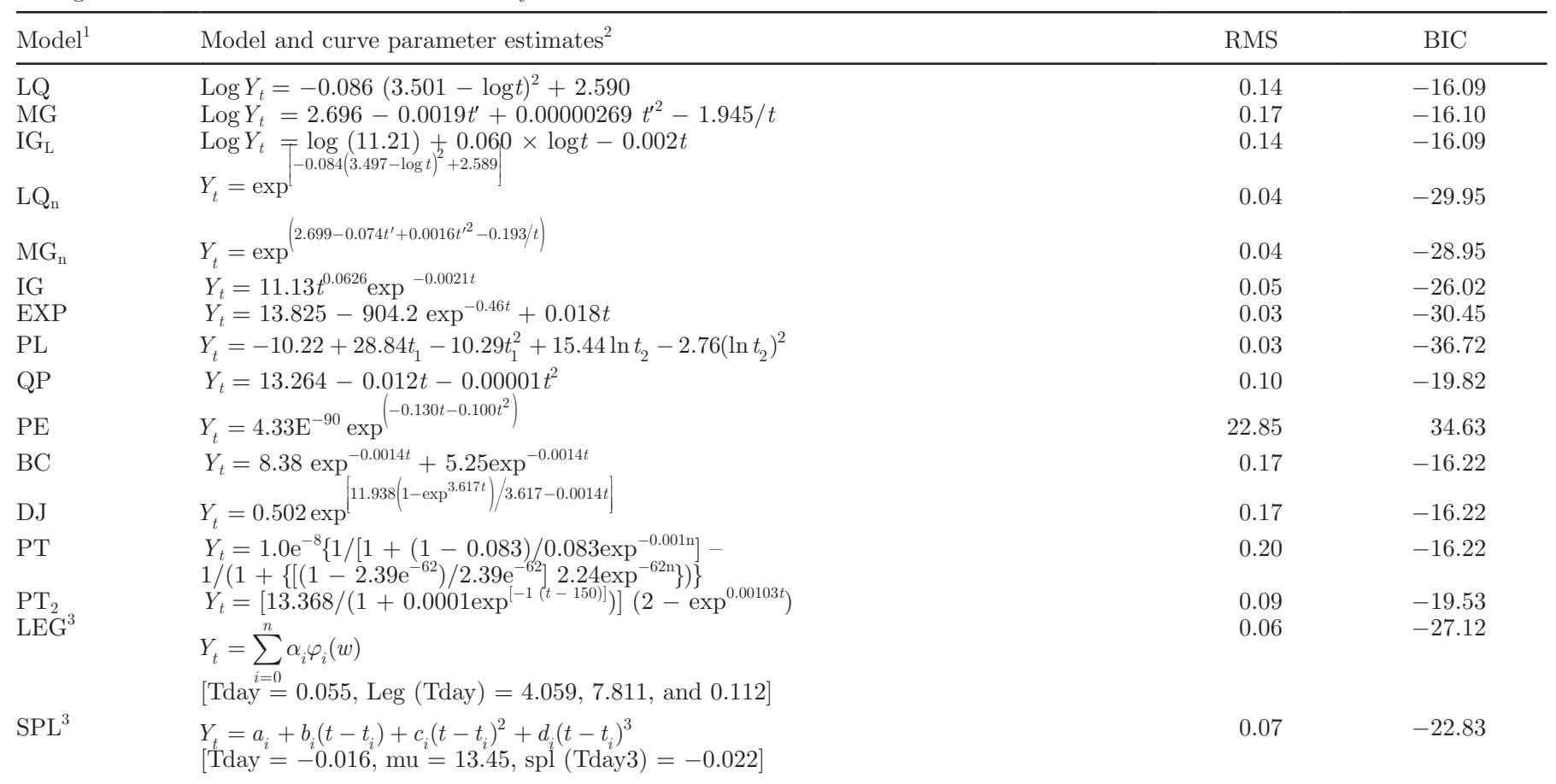

${ }^{1} \mathrm{LQ}=\log$-quadratic (new model); $\mathrm{MG}=$ modified gamma (Morant and Gnanasakthy, 1989); $\mathrm{IG}_{\mathrm{L}}=$ modified incomplete gamma (Wood, 1967); $\mathrm{LQ}_{\mathrm{n}}=$ modified LQ; $\mathrm{MG}_{\mathrm{n}}=$ modified MG; IG = incomplete gamma; EXP = exponential (Wilmink, 1987); PL = polynomial (Ali and Schaeffer, 1987); $\mathrm{QP}=$ quadratic polynomial (Dave, 1971); PE = parabolic exponential (Sikka, 1950); BC = bicompartmental (Ferguson and Boston, 1993); DJ = Dijkstra (Dijkstra et al., 1997); PT = Pollott (Pollott, 2000); $\mathrm{PT}_{2}=$ modified Pollott; LEG = Legendre polynomial (Kirkpatrick et al., 1994); SPL = cubic splines (Green and Silverman, 1994).

${ }^{2} \mathrm{Y}_{\mathrm{t}}=$ test-day milk yield $(\mathrm{L} / \mathrm{d}) ; \mathrm{t}=\mathrm{DIM} ; a, b, c, d, \varphi$, and $w$ are parameters that define the scale and shape of the curve; $\mathrm{t}^{\prime}\left(\mathrm{MG}\right.$ and $\left.\mathrm{MG}_{\mathrm{n}}\right)=$ $(\mathrm{DIM}-150) / 100 ; \mathrm{t}_{1}$ and $\mathrm{t}_{2}(\mathrm{PL})$ are $\mathrm{t} / 305$ and $305 / \mathrm{t}$, respectively; and $\mathrm{n}(\mathrm{PT}$, and PT2) $=\mathrm{t}-150$.

${ }^{3}$ Parameters of the semiparametric models in square brackets; mu = intercept, Tday $=$ slope term, Leg (Tday) and spl(Tday3) are the overall curvature components of the Legendre and Spline models, respectively.

ered less reliable. Criteria (1), (2), and (4) were calculated across all records, whereas criterion (3) was calculated within lactations.

\section{RESULTS}

\section{Average Lactation}

Model parameter estimates, RMS, and BIC of all the fitted models are shown in Table 4 . The goodness of fit as determined by the RMS did not differ significantly among the 3 models fitted with log-transformed milk yield (i.e., $\mathrm{MG}, \mathrm{IG}_{\mathrm{L}}$, and $\mathrm{LQ}$ ). However, RMS was significantly higher $(P<0.05)$ in the $\mathrm{PE}$ and $\mathrm{QP}$ models compared with the other empirical models. Similarly, RMS did not differ among the mechanistic models except the $\mathrm{PT}_{2}$, which had a lower value. Among the semiparametric models, the LEG fitted the AL with less error bias than the SPL. The BIC was lower in the log-transformed empirical and the mechanistic models compared with the other models except the EXP and PL. The average lactation (AL) profile (not shown) of the Holstein-Friesian cow had initial, peak and nadir milk yield $(\mathrm{L} / \mathrm{d})$ of $12.6,13.2$, and 8.9 , respectively. Only the $\mathrm{PT}_{2}$ and the QP models fitted a continuously declining lactation curve (not shown in figure) in contrast to a curve rising to a peak before the decline. The PL and LQ models most accurately predicted the AL as shown in the plot of residuals (Figure 1).

Correlation between predicted and observed milk yields (not shown) was highest in the PL model at 0.997, lowest in the PT model (0.764), and averaged 0.989 for all the models. All models except LQ had highly correlated parameter estimates (not shown). The residuals derived from fitting the various functions to the AL, shown in Figure 1, were generally random except around peak milk yield. All the models achieved similar accuracies in predicting the AL (Figure 1).

Table 5 shows the predicted AL initial, peak, and nadir milk yield (L/d), and 305-d milk yield, lactation 
Table 5. Predicted initial, peak, and 305-d milk yields (L), day at peak, and persistency (mL/d) of lactation obtained from fitting various lactation models to the herd lactation data of pasture-based Holstein-Friesian cows

\begin{tabular}{|c|c|c|c|c|c|c|c|}
\hline \multirow[b]{2}{*}{$\operatorname{Model}^{1}$} & \multicolumn{7}{|c|}{ Predicted milk yield parameter } \\
\hline & Initial & Peak & Peak day & Nadir & 305-d yield & SD & Persistency \\
\hline Actual & 9.73 & 14.2 & 21 & 7.98 & 3,313 & 4.00 & 19.6 \\
\hline LQ & 9.05 & 13.3 & 33 & 8.67 & 3,312 & 3.95 & 18.1 \\
\hline MG & 9.07 & 13.2 & 34 & 9.07 & 3,309 & 3.96 & 18.3 \\
\hline $\mathrm{IG}_{\mathrm{L}}$ & 12.1 & 12.9 & 30 & 8.57 & 3,334 & 3.95 & 16.9 \\
\hline $\mathrm{LQ}_{\mathrm{n}}$ & 9.16 & 13.3 & 33 & 8.79 & 3,316 & 3.97 & 17.8 \\
\hline $\mathrm{MG}_{\mathrm{n}}$ & 8.29 & 13.2 & 32 & 10.6 & 3,315 & 3.96 & 17.7 \\
\hline IG & 12.0 & 12.9 & 31 & 8.65 & 3,354 & 3.95 & 16.8 \\
\hline EXP & -130 & 13.4 & 22 & -130 & 2,945 & 31.8 & 18.0 \\
\hline PL & 5.23 & 13.5 & 30 & 5.23 & 3,303 & 4.21 & 18.0 \\
\hline QP & 13.2 & 13.2 & 4 & 8.67 & 3,351 & 4.04 & 15.3 \\
\hline $\mathrm{PE}$ & 13.2 & 13.2 & 4 & 8.37 & 3,322 & 4.22 & 16.6 \\
\hline $\mathrm{BC}$ & 13.9 & 13.6 & 4 & 8.89 & 3,341 & 4.13 & 15.2 \\
\hline DJ & 13.6 & 13.6 & 4 & 8.89 & 3,339 & 4.13 & 15.3 \\
\hline PT & 12.8 & 12.8 & 4 & 9.46 & 3,335 & 3.91 & 11.0 \\
\hline $\mathrm{PT}_{2}$ & 13.4 & 13.4 & 4 & 12.9 & 3,972 & 13.67 & 14.0 \\
\hline LEG & 12.5 & 13.1 & 21 & 9.07 & 3,326 & 4.00 & 16.5 \\
\hline SPL & 13.4 & 13.4 & 4 & 8.54 & 3,321 & 4.08 & 16.2 \\
\hline
\end{tabular}

${ }^{1} \mathrm{LQ}=\log$-quadratic (new model); MG = modified gamma (Morant and Gnanasakthy, 1989); $\mathrm{IG}_{\mathrm{L}}=\log$-transformed incomplete gamma (Wood, 1967); $\mathrm{LQ}_{\mathrm{n}}=$ modified $\mathrm{LQ} ; \mathrm{MG}_{\mathrm{n}}=$ modified $\mathrm{MG}$; IG = incomplete gamma; $\mathrm{EXP}=$ exponential (Wilmink, 1987); PL = polynomial (Ali and Schaeffer, 1987); $\mathrm{QP}=$ quadratic polynomial (Dave, 1971); PE = parabolic exponential (Sikka, 1950); BC = bicompartmental (Ferguson and Boston, 1993); $\mathrm{DJ}=$ Dijkstra (Dijkstra et al.. 1997) $\mathrm{PT}=$ Pollott (Pollott, 2000) $\mathrm{PT}_{2}=($-parameter modified Pollott): LEG $=$ Legendre polynomial (Kirkpatrick et al., 1994); SPL = cubic splines (Green and Silverman, 1994).

persistency, and days to peak milk yield values. The MG and LQ models gave initial milk yield values closest to the $\mathrm{AL}$, whereas the $\mathrm{IG}_{\mathrm{L}}$ model overpredicted initial milk yield by $2.4 \mathrm{~L}$ compared with 0.65 to 0.67 in the $\mathrm{MG}_{\mathrm{n}}$ and the $\mathrm{LQ}_{\mathrm{n}}$ models, respectively. Of the other models, only PL underpredicted initial milk yield. All models underpredicted peak milk yield by between 0.6 to $1.4 \mathrm{~L} / \mathrm{d}$. The EXP and LEG models most accurately predicted the day on which peak yield occurred. Except EXP and $\mathrm{PT}_{2}$, all models accurately predicted TMY, although predictions were best in both forms of the LQ and MG models (Table 5). All models predicted lactation persistency within 1.5 to $9.6 \mathrm{~mL} / \mathrm{d}$, but the LQ, MG, EXP, and PL models gave the most accurate predictions.

\section{Individual Cow Lactations}

All of the tested models were ranked in order of best to worst goodness of fit based on the comparison of $\mathrm{RMS}_{\mathrm{w}}$ values obtained from equation [5]. The order was $\mathrm{LQ}>\mathrm{MG}>\mathrm{IG}_{\mathrm{L}}$ for the log-transformed models and $\mathrm{MG}_{\mathrm{n}}>\mathrm{PL}>\mathrm{LQ}_{\mathrm{n}}>\mathrm{IG}>\mathrm{PE}>\mathrm{SPL}>\mathrm{QP}>\mathrm{BC}>$ $\mathrm{DJ}>\mathrm{LEG}>\mathrm{PT}>\mathrm{EXP}>\mathrm{PT}_{2}$ for the other models. Based on this ranking, the number of parameters in the model, and the magnitude and distribution of the residuals (Table 5 and Figure 1), 3 models plus the 2 forms of the LQ model were selected for further tests with individual cow lactations and for the evaluation of day at first test-day and number of observations on the goodness of fit. Additional consideration for model selection was to include at least 1 log-transformed, 1 nonlinear, and 1 mechanistic model among the models to be compared with LQ. The selected models were LQ and MG, fitted to log-transformed test-day milk yield, and $\mathrm{LQ}_{\mathrm{n}}, \mathrm{IG}$, and $\mathrm{BC}$ models fitted directly to test-day milk yield. The 5 models were first fitted to all available data (Table 6 ) and then to data partitioned on the basis of restricted data.

\section{Comparison of Models Fitted to Individual Cow Lactations}

Table 6 shows the results for the error criteria used in assessing the goodness of fit of the 5 models fitted to individual cow lactations (DATA1 and DATA2). Mean error, RMS, and their standard errors showed similar trends in the goodness of fit of patterns of all models in both data sets, although the margin of errors was higher in the more variable DATA1, as expected. Higher variation in DATA1 was also reflected in the correlation between observed and predicted values. Mean errors were lowest in the $\mathrm{LQ}_{\mathrm{n}}$ and $\mathrm{MG}$ models compared with IG in DATA1. In contrast, RMS was 
Table 6. Comparison of the goodness of fit criteria of the models fitted to individual cow lactations in entire DATA1 (test-day data, Tasmania) and DATA2 (test-day data, Victoria)

\begin{tabular}{|c|c|c|c|c|c|c|c|c|c|c|}
\hline $\begin{array}{l}\text { Data set/ } \\
\text { model }^{1}\end{array}$ & $\begin{array}{c}\text { Lactations, } \\
\text { no. }\end{array}$ & $\begin{array}{c}\text { Test-days, } \\
\text { no. }\end{array}$ & \multicolumn{8}{|c|}{ Criteria $^{2}$} \\
\hline $\mathrm{BC}$ & 9,502 & 76,761 & -0.08 & 0.024 & 14.0 & 13.12 & 117 & 0.00 & 0.03 & 0.49 \\
\hline $\mathrm{LQ}_{\mathrm{n}}$ & 9,502 & 76,761 & 0.001 & 0.024 & 10.1 & 8.73 & 147 & 0.00 & 0.03 & 0.51 \\
\hline LQ & 9,502 & 76,761 & 0.24 & 2.58 & 0.07 & 0.05 & 104 & 0.00 & 0.02 & 0.99 \\
\hline IG & 2,138 & 19,987 & 0.007 & 0.27 & 8.6 & 2.87 & 55 & 0.00 & 0.08 & 0.77 \\
\hline $\mathrm{BC}$ & 2,138 & 19,987 & -0.02 & 0.03 & 12.4 & 15.5 & 55 & 0.00 & 0.11 & 0.73 \\
\hline $\mathrm{LQ}_{\mathrm{n}}$ & 2,138 & 19,987 & -0.007 & 0.03 & 8.80 & 10.51 & 55 & 0.00 & 0.08 & 0.77 \\
\hline LQ & 2,138 & 19,987 & 0.15 & 0.20 & 0.03 & 0.05 & 57 & 0.00 & 0.09 & 0.99 \\
\hline $\mathrm{MG}$ & 2,138 & 19,987 & 0.12 & 0.17 & 0.03 & 0.05 & 52 & 0.00 & 0.11 & 0.99 \\
\hline
\end{tabular}

${ }^{1}$ Lactation models: IG = incomplete gamma (Wood, 1967), $Y_{(t)}=a t^{b} e^{-c t} ; \mathrm{BC}=$ bicompartmental model (Ferguson and Boston, 1993), $Y_{t}=$ $a e^{-b t}+d e^{-c t} ; \mathrm{LQ}_{\mathrm{n}}=\log$-quadratic (new model), $Y_{t}=\exp \left[a(b-\log t)^{2}\right]+c ; \mathrm{LQ}=\log$-quadratic $\left(\right.$ new model), Log $Y_{(t)}=a(b-\log t)^{2}+c ;$ $\mathrm{MG}=$ modified gamma (Morant and Gnanasakthy, 1989), $\log Y_{t}=a-b t^{\prime}+c t^{2}+d / t$.

${ }^{2}$ Error $=$ mean residuals (difference between daily actual and predicted milk yield) per test-day for every cow; $\mathrm{SD}_{\mathrm{e}}=$ standard error of residuals; RMS = residual mean square (averaged for individual cow lactation); $\mathrm{SD}_{\mathrm{r}}=$ standard error of RMS; W $=$ Wald-Wolfowitz test (number of lactations with random distribution); EXLO = percentage of estimated milk yields lower than or equal to zero; EXHI = percentage of estimated milk yields $>40 \mathrm{~L} ; \mathrm{R}^{2}=$ correlation between actual daily and predicted milk yield.

lower for IG compared with $\mathrm{BC}$ and $\mathrm{LQ}_{\mathrm{n}}$ in DATA2, suggesting that IG may be more suited to fitting data from a more uniform production pattern.

All the models except MG (DATA1) showed a nonrandom distribution of errors (W), suggesting longer than expected runs of negative or positive residuals. The proportion of zero or negative test-day milk yields (EXLO) was highest (3.1\%) for IG, whereas the observed milk yields were generally lower than the expectation $>40$ (EXHI). The correlation between observed and predicted milk yield as measured by $\mathrm{R}^{2}$ among models was lower in DATA1 than in DATA2 and was lowest for IG compared with the other models, except in DATA2 where BC had the lowest $\mathrm{R}^{2}$ values. Mean error, RMS, EXLO, and $\mathrm{R}^{2}$ were similar for the $\mathrm{MG}$ and $\mathrm{LQ}_{\mathrm{n}}$ models in both data sets. The randomness of residuals (W) was also similar for both models in DATA2 although MG had a slightly lower value. The percentage estimated milk yield higher than expectation (EXHI) was higher in DATA2 compared with DATA1 for all models.

\section{Effect of Day at First Test-Day and Available Records on Model Goodness of Fit}

The results of the goodness of fit criteria of the 5 models fitted to the sampled data are shown in Table 7. The IG model was the most affected by the sampled data irrespective of the group or subgroup. Using IG, lactations were better predicted in L60 compared with
G60 (mean error $=0.26-0.43$ vs. $0.47-0.57$ and RMS $=$ $13.6-14.9$ vs. 17.1-20.7, respectively). Similarly, within the L60 subgroups, mean error was highest in L60A and declined with more available data, whereas mean error increased irrespective of number of observations in the G60 group. Mean error tended to remain stable at $0.005 \pm 0.03$ and $0.002 \pm 0.04$ for $B C$ and $L_{2}$, respectively. Prediction error, as determined by RMS, was highest for IG and lowest for $\mathrm{LQ}_{\mathrm{n}}$ although large standard deviations, 24-55 (IG), 10-27 (BC), and 8-16 $\left(\mathrm{LQ}_{\mathrm{n}}\right)$, suggest prediction bias in all the models. Correlation between observed and predicted milk yield $\left(\mathrm{R}^{2}\right)$ for IG also declined with less data in both L60 and G60 groups, declined for $\mathrm{BC}$ in the $\mathrm{L} 60 \mathrm{C}$ and $\mathrm{G} 60 \mathrm{C}$ subgroups and remained stable for $\mathrm{LQ}_{\mathrm{n}}$. However, the number of lactations with a random distribution (W) had similar effects in all models. Significant $P$-values of the Wald-Wolfowitz test were highest for the L60A and the G60A subgroups and smallest for the L60C and G60C sampled subgroups. Nonrandomness of error was similar in all data partitioned groups although the pattern was lower in the G60C group. The mean error of the $\mathrm{BC}$ and $\mathrm{LQ}_{\mathrm{n}}$ models was lower than that for the IG partition group. Both models were equally affected by smaller data size irrespective of day and first test-day, and LQ tended to have the least variation (lower SD) than the other models. The number of available testday records also affected the $\mathrm{R}^{2}$ value more severely for IG than for $\mathrm{BC}$ and $\mathrm{LQn}$, which tended to maintain stable correlation between observed and predicted values partition groups. 
Table 7. Comparison of the goodness of fit criteria of the models fitted to data samples based on differences in days to first test-day and number of observations per cow in DATA1 (test-day data, Tasmania)

\begin{tabular}{|c|c|c|c|c|c|c|c|c|c|c|}
\hline $\begin{array}{l}\text { Model }^{1} / \\
\text { data group }^{2}\end{array}$ & $\begin{array}{l}\text { Lactations, } \\
\text { no. }\end{array}$ & $\begin{array}{c}\text { Test-days, } \\
\text { no. }\end{array}$ & \multicolumn{8}{|c|}{ Criteria $^{3}$} \\
\hline \multicolumn{11}{|l|}{ IG } \\
\hline L60A & 408 & 2,035 & 0.43 & 2.01 & 14.9 & 23.50 & 54 & 4.62 & 0.00 & 0.89 \\
\hline L60B & 500 & 3,308 & 0.29 & 1.55 & 15.0 & 29.85 & 38 & 3.23 & 0.09 & 0.11 \\
\hline L60C & 500 & 4,424 & 0.26 & 1.55 & 13.6 & 27.92 & 5 & 2.82 & 0.04 & 0.28 \\
\hline G60A & 128 & 635 & 0.47 & 2.05 & 20.7 & 55.33 & 23 & 5.51 & 0.00 & 0.29 \\
\hline \multicolumn{11}{|l|}{$\mathrm{BC}$} \\
\hline L60A & 408 & 2,035 & -0.005 & 0.125 & 25.9 & 26.89 & 53 & 0.00 & 0.00 & 0.55 \\
\hline L60B & 500 & 3,308 & -0.006 & 0.015 & 13.11 & 12.08 & 30 & 0.00 & 0.09 & 0.53 \\
\hline L60C & 500 & 4,424 & -0.008 & 0.017 & 13.3 & 10.23 & 3 & 0.00 & 0.04 & 0.46 \\
\hline G60A & 128 & 635 & -0.004 & 0.014 & 16.7 & 13.74 & 25 & 0.00 & 0.00 & 0.58 \\
\hline G60B & 300 & 1,961 & $-9.0 \mathrm{e}^{-4}$ & 0.018 & 10.5 & 11.98 & 5 & 0.00 & 0.00 & 0.52 \\
\hline G60C & 292 & 2,469 & -0.005 & 0.016 & 11.9 & 10.27 & 0 & 0.00 & 0.00 & 0.48 \\
\hline G60B & 300 & 1,961 & 0.003 & 0.122 & 8.1 & 10.52 & 4 & 0.00 & 0.00 & 0.49 \\
\hline G60C & 292 & 2,469 & -0.004 & 0.024 & 93.03 & 8.19 & 0 & 0.00 & 0.00 & 0.50 \\
\hline \multicolumn{11}{|l|}{ LQ } \\
\hline L60A & 408 & 2,035 & 0.23 & 0.20 & 0.09 & 0.09 & 53 & 0.00 & 0.00 & 0.99 \\
\hline L60B & 500 & 3,308 & 0.19 & 0.13 & 0.07 & 0.05 & 10 & 0.00 & 0.15 & 0.99 \\
\hline L60C & 500 & 4,424 & 0.26 & 0.17 & 0.07 & 0.06 & 0 & 0.00 & 0.05 & 0.99 \\
\hline G60A & 128 & 635 & 0.18 & 0.14 & 0.08 & 0.06 & 14 & 0.00 & 0.00 & 0.99 \\
\hline G60B & 300 & 1,961 & 0.20 & 0.14 & 0.09 & 0.05 & 3 & 0.00 & 0.00 & 0.99 \\
\hline G60C & 292 & 2,469 & 0.24 & 0.21 & 0.07 & 0.07 & 0 & 0.00 & 0.00 & 0.99 \\
\hline \multicolumn{11}{|l|}{$\mathrm{MG}$} \\
\hline L60A & 408 & 2,035 & 0.04 & 1.49 & 0.14 & 0.15 & 0 & 0.00 & 0.00 & 0.99 \\
\hline L60B & 500 & 3,308 & -0.03 & 1.33 & 0.03 & 0.06 & 0 & 0.00 & 0.15 & 0.99 \\
\hline L60C & 500 & 4,424 & 0.12 & 1.54 & 0.07 & 0.05 & 0 & 0.00 & 0.05 & 0.99 \\
\hline G60A & 128 & 635 & 0.22 & 1.31 & 0.12 & 0.11 & 0 & 0.00 & 0.00 & 0.99 \\
\hline
\end{tabular}

${ }^{1}$ Lactation models: IG = incomplete gamma (Wood, 1967), $Y_{(t)}=a t^{b} e^{-c t} ; \mathrm{BC}=$ bicompartmental model (Ferguson and Boston, 1993), $Y_{t}=$ $a e^{-b t}+d e^{-c t} ; \mathrm{LQ}_{\mathrm{n}}=\log$-quadratic (new model), $Y_{t}=\exp \left[a(b-\log t)^{2}\right]+c ; \mathrm{LQ}=\log$-quadratic $($ new model $), \log Y_{(t)}=a(b-\log t)^{2}+c$; $\mathrm{MG}=$ modified gamma (Morant and Gnanasakthy, 1989), $\log Y_{t}=a-b t^{\prime}+c t^{2}+d / t$.

${ }^{2}$ Data groups: $\mathrm{L} 60 \mathrm{~A}=$ first test-day $<60$ and 5 observations/cow; L60B $=$ first test-day $<60$ and 6 or 7 observations/cow; L60C $=$ first test-day $<60$ and $>7$ observations/cow; G60A = first test-day $>60$ and 5 observations/cow; G60B = first test-day $>60$ and 6 or 7 observations/cow; and $\mathrm{G} 60 \mathrm{C}=$ first test-day $>60$ and $>7$ observations $/$ cow.

${ }^{3}$ Error $=$ mean residuals (difference between daily actual and predicted milk yield) per test-day for every cow; $\mathrm{SD}_{\mathrm{e}}=$ standard error of residuals; RMS = residual mean square (averaged for individual cow lactation); $\mathrm{SD}_{\mathrm{r}}=$ standard error of RMS; W $=$ Wald-Wolfowitz test (number of lactations with random distribution); EXLO = percentage of estimated milk yields lower or equal to zero; EXHI = percentage of estimated milk yields $>40 \mathrm{~L} ; \mathrm{R}^{2}=$ correlation between actual daily and predicted milk yield.

The LQ model had higher mean error $(0.18-0.24 \pm$ $0.17)$ compared with MG $(-0.03-0.22 \pm 1.40$. In LQ, the mean error increased with more available data in the G60 group, whereas the reverse was observed for MG. Residual mean square was similar in both models across sampled data. For LQ, RMS increased with more available data for the L60 group but increased for MG in the same direction for the G60 group. The WaldWolfowitz run test for the LQ was similar to those observed in the other models. None of the lactations showed a nonrandom error distribution for the MG model. The highest correlations between observed and predicted values were observed for both forms of the LQ and MG models.

\section{DISCUSSION}

The ideal lactation model should be parsimonious, capable of depicting the production pattern, and flexible enough to account for the influence of environmental factors affecting the curve shape without compromising accuracy. In addition, it should fit data from short 
lactations or standard test-day records (Pollott and Gootwine, 2000). The LQ possesses these attributes. Because the performance of the $\mathrm{LQ}, \mathrm{LQ}_{\mathrm{n}}, \mathrm{BC}$, and $\mathrm{MG}$ models was not adversely affected by sampled data, either the L60 or G60 group of these models should be preferred to the IG in fitting shorter lactations, which might be an advantage in pasture-based systems. These attributes of the LQ model and the better fitting throughout lactation with fewer parameters than the MG models suggest its comparative advantage and suitability for modeling lactation in dairy cows. One limitation of the new model is that it tends to emphasize the inflection points of the lactation curve in having parameters that determine both peak milk yield and day at peak. Second, as with the other models, postpeak milk yield lactation, especially around 200 DIM, was not accurately predicted. It was not clear whether this feature is related to milk yield pattern in pasture-based cows or an artifact of the model properties. In autumncalving systems, pasture-based Holstein-Friesian cows are reported to exhibit a second postpeak milk yield in response to turning to pasture (Garcia and Holmes, 2001).

\section{Fitting Lactation Models to Average Lactation}

Although daily milk yields in pasture-based dairy cows are subject to various perturbations such as seasonality of weather affecting pasture availability and quality, calving pattern, and strategic nutrition management, these changes tend to even out at the average herd level, hence the similarities in the goodness of fit of most of the models with the AL data. According to Pollott and Gootwine (2000), any model that will improve on the IG model should be capable of representing early and peak milk yields more accurately than the IG model. Linear transformation of the test-day milk yield $\left(\mathrm{LQ}, \mathrm{MG}\right.$, and $\mathrm{IG}_{\mathrm{L}}$ ) yielded more randomly distributed residuals and improved the goodness of fit over that previously suggested (Cobby and Le Du, 1978; Pollott and Gootwine, 2000) with respect to the IG and MG models, respectively. The 4 best-performing models in this study all had log-transformed components in their mathematical functions. The $\mathrm{MG}, \mathrm{PL}, \mathrm{IG}_{\mathrm{L}}$, and $\mathrm{LQ}$ models achieved better prediction accuracy essentially through improvement in the prediction of early (except PL) and postpeak lactation milk yields, as opposed to the limitation of inaccurate peak milk yield prediction associated with empirical models (Olori et al., 1999; Pollott and Gootwine, 2000; Macciotta et al., 2005; Silvestre et al., 2006). Similar RMS values in all but the PE and QP models suggest little differences in the accuracy of prediction of the models when fitted to average lactation. However, lower BIC in the log-transformed (LQ, MG, and $\mathrm{IG}_{\mathrm{L}}$ ), and the mechanistic (BC, DJ, and PT) models show that these models achieved better prediction compared with the others. The flexibility of the PL, LEG, and SPL functions enhanced better goodness of fit (Silvestre et al., 2006).

\section{Fitting Lactation Curves to Individual Cow Lactations}

Variability in individual cow lactation data can influence the overall model performance (Olori et al., 1999). None of the models except the IG $($ EXLO $=3.10)$ predicted zero milk yield. Setting of lactation at test-day 1 to zero is a known (Tekerli et al., 2000; Silvestre et al., 2006) limitation of the IG model. The LQ and MG models achieved better overall performance than the models fitted directly to milk yield because of lower residuals due to the log-transformation.

The occurrence of atypical lactation patterns in individual cows, which may partly account for poor model fits, can be up to 30\% (Olori et al., 1999; Macciotta et al., 2005; Silvestre et al., 2006). The occurrence of about $24 \%$ atypical lactations in our data might explain the poorer goodness of fit observed in fitting the models to individual cow lactations. Similar results have been observed in previous studies (Berry et al., 2005; Silvestre et al., 2006). The higher residuals in G60B and G60C showed that the performance of IG is influenced by availability of data in early lactation, especially the first $60 \mathrm{~d}$. The results corroborate the suggestion by Pollott and Gootwine (2000) that the poor goodness of fit of many models to individual cow lactations was due to the poor fitting of the incline to the peak yield part of the model, either due to late first recorded test-day or paucity of data in early lactation (i.e., L60A).

\section{CONCLUSIONS}

Lactation models were evaluated for goodness of fit to average and individual cow lactations in a pasturebased dairy system. The parameters of the model remain as previously explained. This model, with biologically interpretable parameters, is easy to fit to either average or individual cow lactation data, and in contrast to the PL and MG models, has 3 parameters that achieve a similar goodness of fit. The unique feature of the model that makes it suitable for diverse lactations modeling is parameter $a$, which fits either an inclining or declining lactation rate from initial milk yield, thus being less constrained by a priori assumption of an incline to peak yield. In addition, fitting the model parameters to the log-transformed milk yield and DIM 
minimizes the residuals and improves goodness of fit. The lactation models tested in this study adequately fitted dairy cow average data, although the PL, MG, $\mathrm{IG}_{\mathrm{L}}$, and LQ models produced more precise lactation parameters. The $\mathrm{LQ}$ and $\mathrm{IG}_{\mathrm{L}}$ are parsimonious in utilizing fewer parameters to achieve the same level of fitness as the PL and MG models. The BC model achieved an all-round better goodness of fit than the other mechanistic models evaluated in this study. The best of the 5 selected models in fitting individual pasture-based Holstein-Friesian cow lactation was LQ followed by MG. It is necessary to routinely model lactation patterns of individual cows for management and breeding decisions. This study confirmed the influence of day at first test-day and number of recorded test-days on the goodness of fit of lactation models. The new model was robust in fitting average or individual cow lactation and is recommended for fitting test-day milk yield in dairy systems. Further testing of the properties of the LQ model and its application to modeling data from other production systems is necessary to determine the robustness of the model.

\section{ACKNOWLEDGMENTS}

This research was funded by a $\mathrm{PhD}$ research scholarship from Dairy Australia (DA, Victoria, Australia), Tasmanian Institute of Agriculture (TIA, Hobart, Tasmania, Australia), and the University of Tasmania (UTAS, Tasmania, Australia). The authors gratefully acknowledge DA, TIA, and UTAS. Our gratitude also goes to Peter Nish and the management of TasHerd (Hadspen, Tasmania), staff and management of Ellinbank Dairy Research Centre, Department of Primary Industries (DPI, Victoria, Australia), and the farmers in both locations who provided access to their data. We also acknowledge John Roche, Dairy NewZealand (New Zealand) for facilitating access to Ellinbank data.

\section{REFERENCES}

Ali, T. E., and L. R. Schaeffer. 1987. Accounting for covariances among test day milk yields in dairy cows. Can. J. Anim. Sci. 67:637-644.

ADHIS (Australian Dairy Herd Improvement Scheme). 2008. The Benefits of Herd Recording. Technical Report 7, version 1, pages 1-2. ADHIS Pty Ltd., Melbourne, Victoria, Australia.

Beever, D. E., A. J. Rook, J. France, M. S. Danoa, and M. Gill. 1991. A review of empirical and mechanistic models of lactation performance by the dairy cow. Livest. Prod. Sci. 29:115-130.

Berry, D. P., V. E. Olori, A. R. Cromie, R. F. Veerkamp, M. Rath, and P. Dillon. 2005. Accuracy of predicting milk yield from alternative milk recording schemes. Anim. Sci. 80:53-60.

Cobby, J. M., and Y. L. P. Le Du. 1978. On fitting curves to lactation data. Anim. Prod. 26:127-133.

Collard, B. L., P. J. Boettcher, J. C. M. Dekkers, D. Peticlerc, and L. R. Schaeffer. 2000. Relationships between energy balance and health traits of dairy cattle in early lactation. J. Dairy Sci. 83:2683-2690.

Congleton, J. R., and R. W. Everett. 1980. Application of the incomplete gamma function to predict cumulative milk production. J. Dairy Sci. 63:109-119.

Constantinides, A. 1988. Applied Numerical Methods with Personal Computers. 2nd ed. McGraw-Hill, New York, NY.

Dairy Australia. 2008. Australia dairy industry in focus: 2007. Accessed May 5, 2012. http://future.aae.wisc.edu/publications/Final_InFocus2007.pdf.

Dave, B. K. 1971. First lactation curve of Indian water buffalo. JNKVV Res. J. 5:93.

Dijkstra, J., J. France, M. S. Dhanoa, J. A. Maas, M. D. Hanigan, A. S. Rook, and D. E. Beever. 1997. A model to describe growth patterns of the mammary gland during pregnancy and lactation. J. Dairy Sci. 80:2340-2354.

Ferguson, J. D., and R. Boston. 1993. Lactation curves analysis: Comparison of gamma function, polynomial and exponential methods towards a mechanistic model of milk production. J. Dairy Sci. 76(Suppl. 1):268. (Abstr.)

Garcia, S. C., and C. W. Holmes. 2001. Lactation curves of autumnand spring-calved cows in pasture-based dairy systems. Livest. Prod. Sci. 68:189-203.

Gilmour, A. R., B. J. Gogel, B. R. Cullis, S. J. Welham, and R. Thompson. 2002. ASReml User Guide Release 1.0. VSN International Ltd., Hemel Hempstead, UK.

Green, P. J., and B. W. Silverman. 1994. Nonparametric regression and generalized linear models. A roughness penalty approach. Chapman \& Hall, London, UK.

Grossman, M., and W. Koops. 2003. Modelling extended lactation curves of dairy cattle: A biological basis for the multi-phasic approach. J. Dairy Sci. 86:988-998.

Jensen, J. 2001. Genetic evaluation of dairy cattle using test-day models. J. Dairy Sci. 84:2803-2812.

Kirkpatrick, M., W. G. Hill, and R. Thompson. 1994. Estimating the covariance structure of traits during growth and ageing, illustrated with lactation in dairy cattle. Genet. Res. 64:57-69.

Knight, C. H., M. Peaker, and C. J. Wilde. 1998. Local control of mammary development and function. Rev. Reprod. 3:104-112.

Knight, C. H., and C. J. Wilde. 1993. Mammary cell changes during pregnancy and lactation. Livest. Prod. Sci. 35:3-19.

Kolver, E. S., and S. B. Muller. 1998. Performance and nutrient intake of high producing Holstein cows consuming pasture or a total mixed ration. J. Dairy Sci. 81:1403-1411.

Leonard, T., and J. S. J. Hsu. 2001. Bayesian Methods. Cambridge University Press, Cambridge, UK.

Macciotta, N. P. P., D. Vicario, and A. Cappio-Borlino. 2005. Detection of different shapes of lactation curve for milk yield in dairy cattle by empirical mathematical models. J. Dairy Sci. 88:11781191.

Morant, S. V., and A. Gnanasakthy. 1989. A new approach to the mathematical formulation of lactation curves. Anim. Prod. 49:151-162.

Neal, H. D., and J. M. H. Thornley. 1983. The lactation curve in dairy cattle: A mathematical model of the mammary gland. J. Agric. (Camb.) 101:389-400.

Olori, V. E., S. Brotherstone, W. G. Hill, and B. J. McGuirk. 1999. Estimating variance components for test day milk records by restricted maximum likelihood with random regression animal model. Livest. Prod. Sci. 61:53-63.

Papajcsik, I. A., and J. Bodero. 1988. Modelling lactation curves of Friesian cows in a sub-tropical climate. Anim. Prod. 47:201-205.

Pollott, G. E. 2000. A biological approach to lactation curve analysis for milk yield. J. Dairy Sci. 83:2448-2458.

Pollott, G. E., and E. Gootwine. 2000. Appropriate mathematical models for describing the complete lactation of dairy sheep. Anim. Sci. 71:197-207.

SAS Institute. 2002. User's Guide Version 9.1. SAS Institute Inc., Cary, NC.

Schaeffer, L. R. 2004. Application of random regression models in animal breeding. Livest. Prod. Sci. 86:35-45. 
Sherchand, L., R. W. McNew, D. W. Kellog, and Z. B. Johnson. 1995. Selection of a mathematical model to generate lactation curves using daily milk yields of Holstein cows. J. Dairy Sci. 78:2507-2513.

Sikka, L. C. 1950. A study of lactation as affected by heredity and environment. J. Dairy Res. 17:231-252.

Silvestre, A. M., F. Petim-Batista, and J. Colaço. 2006. The accuracy of seven mathematical functions in modelling dairy cattle lactation curves based on test-day records from varying sample schemes. J. Dairy Sci. 89:1813-1821.

Tekerli, M., Z. Akinci, I. Dogan, and A. Akcan. 2000. Factors affecting the shape of lactation curves of Holstein cows from the Balikesir province of Turkey. J. Dairy Sci. 83:1381-1386.

Tozer, P. R., and R. G. Huffaker. 1999. Mathematical equations to describe lactation curves for Holstein-Friesian cows in New South Wales. Aust. J. Agric. Res. 50:431-440.
Val-Arreola, D., E. Kebreab, J. Dijkstra, and J. France. 2004. Study of the lactation curve in dairy cattle on farms in Central Mexico. J. Dairy Sci. 87:3789-3799.

White, I. M. S., R. Thompson, and S. Brotherstone. 1999. Genetic and environmental smoothing of lactation curves with cubic splines. J. Dairy Sci. 82:632-638.

Wilmink, J. B. M. 1987. Adjustment of lactation yield for age at calving in relation to level of production. Livest. Prod. Sci. 16:321334.

Wood, P. D. P. 1967. Algebraic model of the lactation curve in cattle. Nature 216:164-165. 